\title{
Hydrogen-Nitrogen Greenhouse Warming in Earth's Early Atmosphere
}

\section{Citation}

Wordsworth, Robin, and Raymond Pierrehumbert. 2013. “Hydrogen-Nitrogen Greenhouse Warming in Earth's Early Atmosphere." Science 339 (6115) (January 3): 64-67. doi:10.1126/ science.1225759. http://dx.doi.org/10.1126/science.1225759.

\section{Published Version}

doi:10.1126/science.1225759

\section{Permanent link}

http://nrs.harvard.edu/urn-3:HUL.InstRepos:27877657

\section{Terms of Use}

This article was downloaded from Harvard University's DASH repository, and is made available under the terms and conditions applicable to Open Access Policy Articles, as set forth at http:// nrs.harvard.edu/urn-3:HUL.InstRepos:dash.current.terms-of-use\#OAP

\section{Share Your Story}

The Harvard community has made this article openly available.

Please share how this access benefits you. Submit a story.

\section{Accessibility}




\title{
Hydrogen-nitrogen greenhouse warming in Earth's early atmosphere
}

\author{
Robin Wordsworth ${ }^{1 *}$ and Raymond Pierrehumbert, ${ }^{1}$ \\ ${ }^{1}$ Department of Geological Sciences, University of Chicago, Chicago, IL 60637, USA \\ *To whom correspondence should be addressed; E-mail: rwordsworth @ uchicago.edu.
}

Understanding how Earth has sustained surface liquid water throughout its history remains a key challenge, given that the Sun's luminosity was much lower in the past. Here we show that with an atmospheric composition consistent with the most recent constraints, the early Earth would have been significantly warmed by $\mathrm{H}_{2}-\mathrm{N}_{2}$ collision-induced absorption. With $2-3$ times the present-day atmospheric mass of $\mathrm{N}_{2}$ and a hydrogen mixing ratio of $0.1, \mathrm{H}_{2}$ $\mathbf{N}_{2}$ warming is sufficient to raise global mean surface temperatures above $0{ }^{\circ} \mathrm{C}$ under $\mathbf{7 5} \%$ solar flux with $\mathbf{C O}_{2}$ levels only $\mathbf{2 - 2 5}$ times present-day values. Depending on their time of emergence and diversification, early methanogens may have caused global cooling via the conversion of hydrogen and carbon dioxide to methane, with potentially observable consequences in the geological record.

One of the most durable questions about Earth's early climate arises from the faint young Sun effect: because progressive accumulation of helium in a star's core causes its luminosity to increase with age (1), the solar energy incident on Earth was significantly lower ( $\sim 75 \% 3.8$ 
Ga) during the Hadean and Archean eras (2). As geological evidence shows Earth was not in a globally glaciated, snowball state throughout this time (3), additional mechanisms must have been present to warm the climate.

Previous explanations for this altered climate have included increased atmospheric ammonia or methane, a decreased surface albedo, and changes in the distribution of clouds $(2,4,5)$. However, all of these mechanisms have subsequently been shown to suffer important defects $(6,7)$. Increased atmospheric carbon dioxide is one plausible solution because of the climate buffer provided by the crustal carbonate-silicate cycle (8), but efficient mantle $\mathrm{CO}_{2}$ cycling in the Hadean and Archean probably reduced the strength of this feedback (9). Interpretation of the geological record is difficult, but analyses of mid to late Archean paleosols suggest between around 10 and 50 times the present atmospheric pressure $(\mathrm{PAL})$ of $\mathrm{CO}_{2}(7,10)$. Even lower values (around $3 \times \mathrm{PAL}$ ) have been derived from analysis of magnetite and siderite equilibria in Archean banded iron formations, although the underlying assumptions behind these limits have been questioned $(5,7)$.

One recently proposed mechanism for counteracting the faint young Sun is pressure-induced broadening of the absorption lines of existing greenhouse gases due to increased atmospheric nitrogen, which alone should cause a warming of between 3 and $8 \mathrm{~K}(11)$. Recent attempts to estimate atmospheric density from fossil raindrop imprints suggest a value near that of the present day around $2.7 \mathrm{Ga}$, with an upper limit of double the present value (12). However, the mantle has a large $\mathrm{N}$ inventory that is correlated with radiogenic ${ }^{40} \mathrm{Ar}$ but not primordial ${ }^{36} \mathrm{Ar}$, indicating that it originated from subducted crust, where it had most likely been fixed biologically. It is therefore likely that on the pre-biotic / early Archean Earth, the atmospheric nitrogen content was around 2-3 times the present-day value (11).

Hydrogen, the most abundant gas in the Solar System, has previously been ignored in the Archean climate budget, presumably because it was long thought to be a minor constituent even 
in the early atmosphere (13). After the initial loss of Earth's primordial hydrogen envelope, the mixing ratio of $\mathrm{H}_{2}$ in the atmosphere was primarily determined by a balance between outgassing, surface/ocean chemistry, and escape to space. It was long believed that escape of $\mathrm{H}_{2}$ in the Archean was rapid, with diffusion from the lower atmosphere to the exobase the limiting factor, as it is today. However, recent numerical calculations imply that the rate of hydrodynamic $\mathrm{H}_{2}$ escape on the early Earth was more strongly constrained by the adiabatic cooling of the escaping gas given a limited XUV energy input (14-16). As a result, hydrogen could have been a major constituent (up to $\sim 30 \%$ by volume) of the Archean atmosphere unless surface or ocean biogeochemistry continuously removed it.

A single $\mathrm{H}_{2}$ molecule is homonuclear and diatomic and hence has no direct vibrational or rotational absorption bands. Nonetheless, molecular hydrogen interacts strongly with infrared radiation via collision-induced absorption (CIA), the strength of which scales with the product of the densities of the two interacting gases. CIA has been well-studied for the gas giant planets and Titan, where it dominates radiative transfer in the middle and lower portions of the atmosphere $(17,18)$. On early Earth, nitrogen and hydrogen may both have been abundant in the atmosphere, so interacting pairs of $\mathrm{N}_{2}-\mathrm{N}_{2}, \mathrm{H}_{2}-\mathrm{N}_{2}$ and $\mathrm{H}_{2}-\mathrm{H}_{2}$ should all be considered as potential contributors to greenhouse warming.

Figure 1a shows the $\mathrm{H}_{2}$ and $\mathrm{N}_{2}$ CIA bands alongside absorption bands of the other main greenhouse gases in the primitive atmosphere. While $\mathrm{N}_{2}-\mathrm{N}_{2}$ dimer absorption is strong in the 0-300 $\mathrm{cm}^{-1}$ part of the spectrum, it is overwhelmed by $\mathrm{H}_{2} \mathrm{O}$ absorption and is too far from the peak of blackbody emission at terrestrial temperatures to have a significant effect. $\mathrm{H}_{2}-\mathrm{H}_{2}$ absorbs over a much broader spectral range, but the dependence of CIA on the squared density of the gas means that even for the upper limit estimates of $\mathrm{H}_{2}$ mixing ratios, its overall effect is small. The $\mathrm{N}_{2}-\mathrm{H}_{2}$ band, however, absorbs strongly, and it peaks near the critical 750-1200 $\mathrm{cm}^{-1}$ 'window' region where the contribution of all the other gases to opacity is small. 
To investigate the climatic effects of this previously neglected opacity, we performed 1D radiative-convective simulations for a range of plausible Archean atmospheric compositions. We used a correlated- $k$, two-stream radiative transfer scheme (19) with 80 bands in the infrared and 36 bands in the visible. Temperature-pressure profiles were created over 80 vertical levels, with moist adiabatic adjustment assumed when the temperature profile became unstable to convection. A solar flux of $75 \%$ the present-day level $\left(1024.5 \mathrm{~W} \mathrm{~m}^{-2}\right)$ was assumed and the surface albedo was set to $0.23(20)$.

Fig. 1b shows the the resulting decrease in outgoing longwave radiation (OLR) in each band due to the presence of hydrogen for an atmosphere with the same composition as shown in Fig. 1a. The OLR is significantly reduced in the $750-1200 \mathrm{~cm}^{-1}$ window region and around $500 \mathrm{~cm}^{-1}$, while minor increases occur around the $15 \mu \mathrm{m} \mathrm{CO} \mathrm{CO}_{2}$ absorption band due to the decrease in atmospheric lapse rate as hydrogen levels increase. Because the $\mathrm{H}_{2}-\mathrm{N}_{2}$ absorption spectrum overlaps with those of water vapor and carbon dioxide, radiative forcing from $\mathrm{H}_{2}$ $\mathrm{N}_{2}$ is highest when these gases are scarce. The radiative forcing also increases strongly with the atmospheric nitrogen content because of the dependence of CIA on the density of each interactant. At the present atmospheric mass (PAL) of $\mathrm{N}_{2}$ (results not shown), $\mathrm{H}_{2}-\mathrm{N}_{2}$ CIA provides only a few $\mathrm{W} \mathrm{m}^{-2}$, while for temperatures of $280 \mathrm{~K}$ or less in the 'high' warming scenario with $\mathrm{PAL} \mathrm{CO}_{2}$, radiative forcing exceeds $25 \mathrm{~W} \mathrm{~m}^{-2}$ (Table 1; Fig. 2b) (21).

To determine the increase in equilibrium surface temperature under this forcing, we next ran the radiative-convective model in time-stepping mode. Figures $2 \mathrm{c}$-e shows that when atmospheric nitrogen is elevated, higher hydrogen mixing ratios cause significant increases in surface temperature. At PAL $\mathrm{N}_{2}, \mathrm{H}_{2}-\mathrm{N}_{2}$ CIA causes at most $2-3 \mathrm{~K}$ warming, but this rises to $10-15 \mathrm{~K}$ as nitrogen levels are increased. Given a $\mathrm{H}_{2}$ mixing ratio of $10 \%$ and $2 \times \mathrm{PAL} \mathrm{N}_{2}$, mean surface temperatures exceed the melting point of water for $\mathrm{CO}_{2}$ levels $\sim 25 \times$ PAL. At $3 \times$ PAL N $\mathrm{N}_{2}$, only $\sim 2 \times \mathrm{PAL} \mathrm{CO}_{2}$ is required. 
To what extent could hydrogen-nitrogen warming have influenced the evolution of Earth's early climate? We can begin by considering the limiting case where no significant biological alteration of the atmosphere occurred. Then, the hydrogen abundance in the early atmosphere can be determined by a simple balance between volcanic outgassing and escape to space, based on atmospheric redox balance in the absence of significant organic burial (22). Abiotic $\mathrm{CO}_{2}$ levels can then be estimated by assuming that the carbonate-silicate temperature-weathering feedback (8) operated on 1-10 Myr timescales, driving atmospheric $\mathrm{CO}_{2}$ downward to a level dependent on the solar flux and the amount of $\mathrm{H}_{2}$ and $\mathrm{N}_{2}$ in the atmosphere (23). Figure 3 shows estimated $\mathrm{CO}_{2}$ concentrations under $75 \%$ the present-day solar flux for various $\mathrm{CO}_{2}$ outgassing rates, assuming no biological alteration of the atmosphere. Seafloor weathering is neglected in the calculation (9), so the $\mathrm{CO}_{2}$ levels shown are most likely overestimated. Even so, it is clear that high $\mathrm{H}_{2}$ and $\mathrm{N}_{2}$ could easily have reduced atmospheric $\mathrm{CO}_{2}$ to below $100 \times \mathrm{PAL}$ even under $75 \%$ solar flux.

After the emergence of life, the extent of biological alteration of the atmosphere was dependent on the energy source and net productivity of the dominant ecosystem. Of particular interest in the context of $\mathrm{H}_{2}$-rich atmospheres are methanogens, which feed on the chemical energy released by combining carbon dioxide and hydrogen in the reaction $\mathrm{CO}_{2}+4 \mathrm{H}_{2} \rightarrow \mathrm{CH}_{4}+2 \mathrm{H}_{2} \mathrm{O}$. Phylogenetic analyses suggests these organisms evolved at some point in the mid-Archean, with hyperthermophilic methanogenesis preceding the mesophilic adaptation by at least several hundred Myr $(24,25)$. While in small quantities methane causes warming, its potential as a greenhouse gas is limited by the separation of its main absorption band from the peak of blackbody absorption (Fig. 1a) and its conversion to photochemical haze for $\left[\mathrm{CH}_{4}\right] /\left[\mathrm{CO}_{2}\right]$ ratios greater than $\sim 0.1$, which tends to have a cooling effect $(6)$.

For methanogens to have increased surface temperatures after their emergence, therefore, the biological conversion of $\mathrm{CO}_{2}$ and $\mathrm{H}_{2}$ to $\mathrm{CH}_{4}$ must have balanced $\mathrm{CH}_{4}$ photolysis due 
to the solar UV flux at relatively low atmospheric $\mathrm{CH}_{4}$ levels. Estimates of the $\mathrm{CH}_{4}$ photolysis rate under the elevated UV/Lyman- $\alpha$ fluxes expected in the Archean are in the range $2-5 \times 10^{11} \mathrm{~cm}^{-2} \mathrm{~s}^{-1}$ for hydrogen-rich atmospheres (26). For comparison, the present-day biogenic methane flux is of order $1 \times 10^{11} \mathrm{~cm}^{-2} \mathrm{~s}^{-1}$ (26). Ecosystem models that assume no nutrient or climate constraints for biological productivity yield steady-state $\left[\mathrm{CH}_{4}\right] /\left[\mathrm{H}_{2}\right]$ ratios of around 0.03 if $\mathrm{H}_{2}$ is initially abundant, implying an extremely hazy atmosphere and little warming from $\mathrm{H}_{2}-\mathrm{N}_{2}$ CIA (26). However, in the early Archean the reduced continental area and increased ocean volume likely made nutrient and habitat limitations significantly more stringent than they are today (27).

If habitat limitations were not important, emergent methanogens in an early climate dominated by $\mathrm{H}_{2}-\mathrm{N}_{2}$ and $\mathrm{CO}_{2}$ warming would have continued to consume $\mathrm{H}_{2}$ and $\mathrm{CO}_{2}$ rapidly until global cooling became the limiting factor on biological productivity (28). In the most drastic scenario, global glaciation would result, followed by a build-up of $\mathrm{CO}_{2}$ and $\mathrm{H}_{2}$ levels until the climate warmed again. The Earth was ice-free throughout most of the Archean, but geological evidence exists for an early glaciation event 2.8-2.9 Ga (29), which may have been caused by the rise of methanogenesis. Understanding the detailed effects of the early biosphere on climate requires 3D climate simulations coupled with models of the (local) dependence of ecosystem productivity on surface temperature and nutrient availability. This is an important topic for future study.

Methanogens are often assumed to have been an integral part of the early Archean ecosystem because a methane greenhouse was believed necessary to solve the faint young Sun problem. In contrast, our results show that an early climate dominated by abiotic $\mathrm{H}_{2}-\mathrm{N}_{2}$ and $\mathrm{CO}_{2}$ warming is consistent with both observational and theoretical limits on atmospheric $\mathrm{CO}_{2}$ levels and phylogenetic analyses suggesting later diversification of the Archaea. Hydrogen-nitrogen warming is also likely to be important in the search for biosignatures on super-Earth exoplanets, whose 
higher masses imply lower energy-limited hydrogen escape rates and larger typical atmospheric nitrogen inventories. Because incident XUV flux is a function of orbital distance, $\mathrm{H}_{2}-\mathrm{N}_{2}$ warming may be of particular importance to the habitability of terrestrial exoplanets that are far from their host stars.

\section{References and Notes}

1. D. O. Gough, Solar Physics 74, 21 (1981).

2. C. Sagan, G. Mullen, Science 177, 52 (1972).

3. W. H. Peck, J. W. Valley, S. A. Wilde, C. M. Graham, Geochimica et Cosmochimica Acta 65, 4215 (2001).

4. A. A. Pavlov, L. L. Brown, J. F. Kasting, Journal of Geophysical Research 106, 23267 (2001).

5. M. T. Rosing, D. K. Bird, N. H. Sleep, C. J. Bjerrum, Nature 464, 744 (2010).

6. J. D. Haqq-Misra, S. D. Domagal-Goldman, P. J. Kasting, J. F. Kasting, Astrobiology 8, 1127 (2008).

7. G. Feulner, Reviews of Geophysics 50, G2006 (2012).

8. J. C. G. Walker, P. B. Hays, J. F. Kasting, Journal of Geophysical Research 86, 9776 (1981).

9. N. H. Sleep, K. Zahnle, Journal of Geophysical Research 106, 1373 (2001).

10. S. G. Driese, et al., Precambrian Research 189, 1 (2011).

11. C. Goldblatt, et al., Nature Geoscience 2, 891 (2009). 
12. S. Som, D. Catling, J. Harnmeijer, P. Polivka, R. Buick, Nature 484, 359 (2012).

13. For exosolar planets, it has been suggested that hydrogen could enable planetary habitability in certain cases, but only in quantities of 1 bar or more due to direct $\mathrm{H}_{2}-\mathrm{H}_{2} \mathrm{CIA}$ (30-32). This mechanism was considered and dismissed for the early Earth in (2).

14. A. J. Watson, T. M. Donahue, J. C. G. Walker, Icarus 48, 150 (1981).

15. F. Tian, O. B. Toon, A. A. Pavlov, H. De Sterck, Science 308, 1014 (2005).

16. The calculations in (15) did not take non-thermal escape or heating due to heavier gases into account, leading to some claims that they underestimated the total $\mathrm{H}_{2}$ escape (33). However, non-thermal escape is only dominant on the present-day Earth and should have been limited in the Archean (34), and infrared emission from radiatively active neutral species such as $\mathrm{CO}_{2}$ causes significant cooling of the thermosphere. A final assessment of the hydrogen escape rates from Earth's early atmosphere awaits development of 3D multicomponent hydrodynamic escape models with coupled radiative transfer and chemistry.

17. A. Borysow, L. Frommhold, The Astrophysical Journal 303, 495 (1986).

18. C. P. McKay, J. B. Pollack, R. Courtin, Science 253, 1118 (1991).

19. R. Wordsworth, et al., Astronomy and Astrophysics 522, A22+ (2010).

20. Materials and methods are available as Supporting Online Material (SOM) on Science Online.

21. Here we use the term PAL to refer to present-day atmospheric partial pressure for $\mathrm{CO}_{2}$, but present-day atmospheric mass for $\mathrm{N}_{2}$. For all simulations, we first fix the mixing ratios of each gas and the total mass column of $\mathrm{N}_{2}, M_{N_{2}}$. We then calculate the total atmospheric 
pressure as $p_{t o t}=g M_{N_{2}} \bar{\mu} / \mu_{N_{2}} f_{N_{2}}$, where $g$ is gravity, $\bar{\mu}$ is the mean molar mass, and $f_{N_{2}}$ and $\mu_{N_{2}}$ are the volume mixing ratio and molar mass of nitrogen, respectively. The partial pressure of $\mathrm{CO}_{2}$ is then simply $p_{t o t} f_{\mathrm{CO}_{2}}$.

22. J. F. Kasting, D. E. Canfield, The Global Oxygen Cycle (John Wiley \& Sons, Ltd, 2012), pp. 93-104.

23. To produce Fig. 3 we expressed the $\mathrm{CO}_{2}$ carbonate-silicate weathering rate as $\frac{W}{W_{0}}=$ $\beta_{0} \frac{\gamma}{\gamma_{0}}\left(1+a_{P}\left(T_{\text {surf }}-T_{0}\right)\right)^{a}\left(\frac{p_{C O_{2}}}{p_{C O_{2} 0}}\right)^{b} \exp \left(\frac{T_{\text {surf }}-T_{0}}{T_{U}}\right)$ (35). We then set $W$ equal to the assumed $\mathrm{CO}_{2}$ outgassing rate $\Gamma_{C_{2}}$ and calculated $T_{\text {surf }}$ as a function of the $\mathrm{CO}_{2}$ partial pressure $p_{\mathrm{CO}_{2}}$ using results from the radiative-convective model. See SOM for a definition of all terms and justification of the method.

24. C. H. House, B. Runnegar, S. T. Fitz-Gibbon, Geobiology 1, 15 (2003).

25. C. E. Blank, Geobiology 7, 495 (2009).

26. P. Kharecha, J. Kasting, J. Siefert, Geobiology 3, 53 (2005).

27. Modern ocean net primary productivity is concentrated in shallow regions close to continents (26), but in the early Archean, the continental crust volume was $\sim 3$ times lower and the ocean volume may have been up to 25 percent greater than today $(36,37)$. In the deep ocean away from submarine vents, rates of $\mathrm{H}_{2}$ supply would be reduced by $\sim 10^{3}$ compared to the mixed layer, implying a decrease of biological productivity there by a similar factor (26).

28. Indirectly, abundant methanogenesis could also have caused global cooling via drawdown of atmospheric nitrogen. In atmospheres with $1000 \mathrm{ppm} \mathrm{CH}_{4}$, atmospheric $\mathrm{HCN}$ production rates via photolysis can reach $1 \times 10^{10} \mathrm{~cm}^{-2} \mathrm{~s}^{-1}(38)$. Without a mechanism to reform $\mathrm{N}_{2}$, 
this could cause the removal of the entire present-day atmospheric nitrogen inventory on a timescale of order $100 \mathrm{My}$.

29. G. M. Young, V. von Brunn, D. J. C. Gold, W. E. L. Minter, The Journal of Geology 106, pp. 523 (1998).

30. D. J. Stevenson, Nature 400, 32 (1999).

31. R. Pierrehumbert, E. Gaidos, The Astrophysical Journal Letters 734, L13 (2011).

32. R. Wordsworth, Icarus 219, 267 (2012).

33. D. C. Catling, Science 311, 38 (2006).

34. F. Tian, O. B. Toon, A. A. Pavlov, Science 311, 38 (2006).

35. D. S. Abbot, N. B. Cowan, F. J. Ciesla, The Astrophysical Journal 178, 756 (2012).

36. B. Dhuime, C. J. Hawkesworth, P. A. Cawood, C. D. Storey, Science 335, 1334 (2012).

37. E. C. Pope, D. K. Bird, M. T. Rosing, Proceedings of the National Academy of Sciences (2012).

38. F. Tian, J. F. Kasting, K. Zahnle, Earth and Planetary Science Letters 308, 417 (2011).

39. Climate calculations were performed on the iDataPlex computational cluster of the Université de Paris 6, France. RW thanks S. Lewis, J. Waldbauer, C. Goldblatt, N. Dauphas, M. Coleman and D. Abbot for insightful discussions. 
Table 1: Definitions of the atmospheric scenarios used in Figs. 2 and 3.

\begin{tabular}{c|c|c}
\hline & $\mathrm{N}_{2}$ mass column $\left[\mathrm{kg} \mathrm{m}^{-2}\right]$ & $\mathrm{H}_{2}$ volume mixing ratio [mol/mol] \\
\hline Present-day & $7.80 \times 10^{3}$ & 0.0 \\
Moderate & $1.56 \times 10^{4}$ & 0.05 \\
High & $2.34 \times 10^{4}$ & 0.1
\end{tabular}
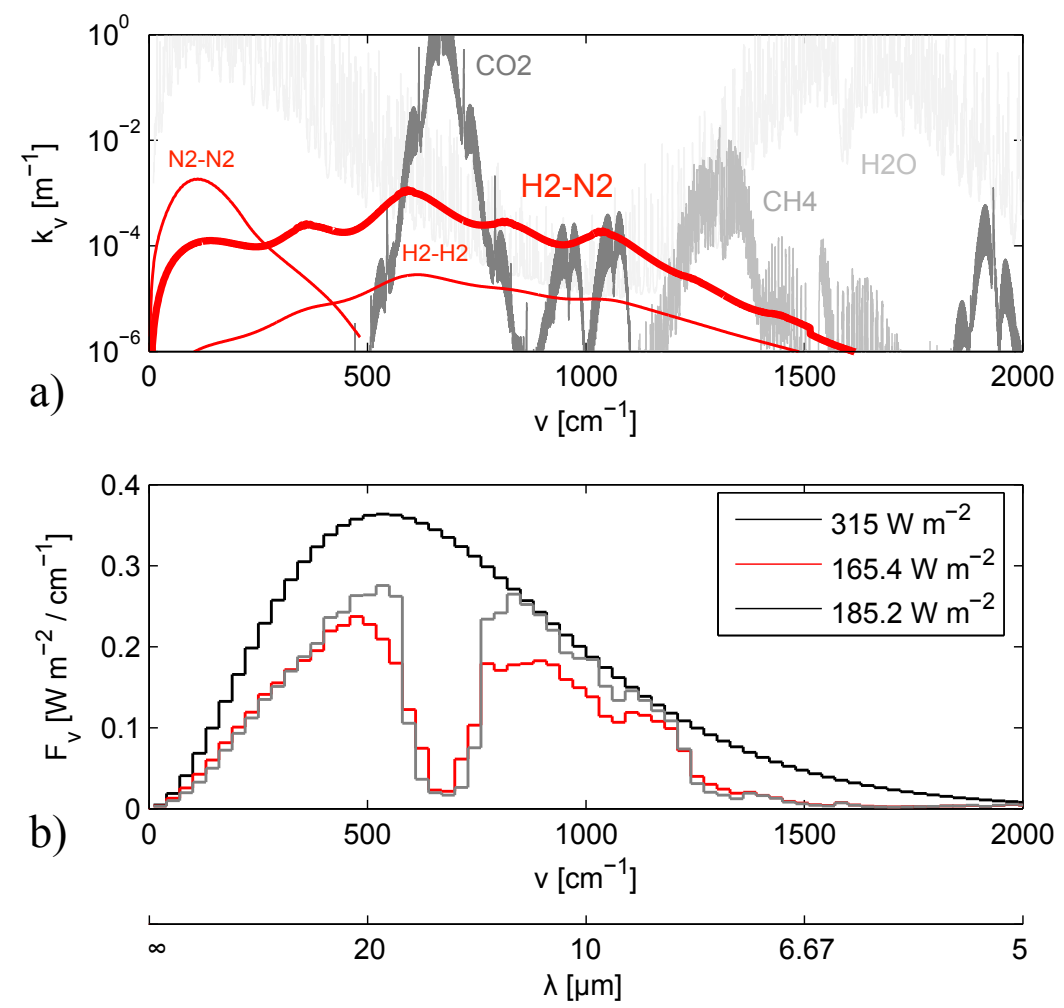

Figure 1: a) Infrared absorption at the surface for an Archean atmosphere with $\times 3$ PAL $\mathrm{N}_{2}$, $10 \% \mathrm{H}_{2}, 1700 \mathrm{ppm} \mathrm{CO}_{2}(\sim 10 \times \mathrm{PAL}), 5 \mathrm{ppm} \mathrm{CH}_{4}$, surface temperature $273 \mathrm{~K}$ and relative humidity 0.77 . b) Corresponding outgoing longwave radiation (OLR) assuming line absorption only (gray line) and with CIA included (red line). Black line shows the blackbody emission at $273 \mathrm{~K}$, while the numbers in the box show the integrated OLR for each case. See SOM for calculation details. Given high atmospheric hydrogen and nitrogen levels, $\mathrm{H}_{2}-\mathrm{N}_{2}$ absorption dominates in the $750-1200 \mathrm{~cm}^{-1}$ spectral region where the bands of the other greenhouse gases are relatively weak. 

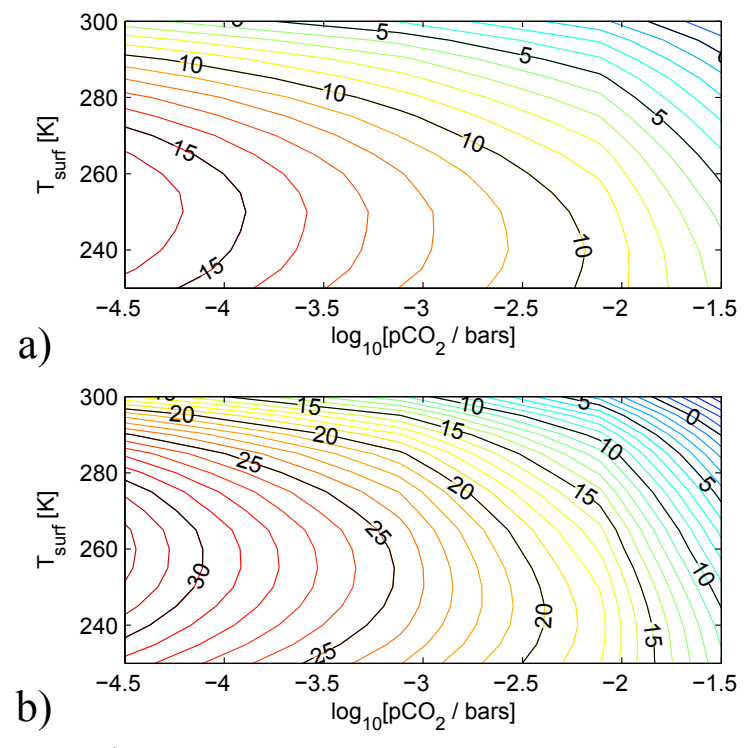

b)

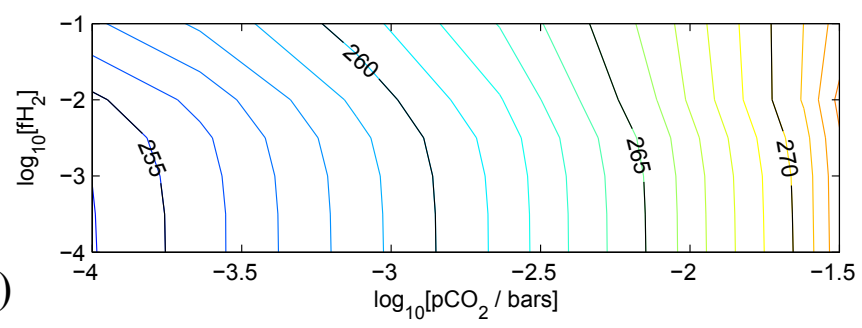

d)

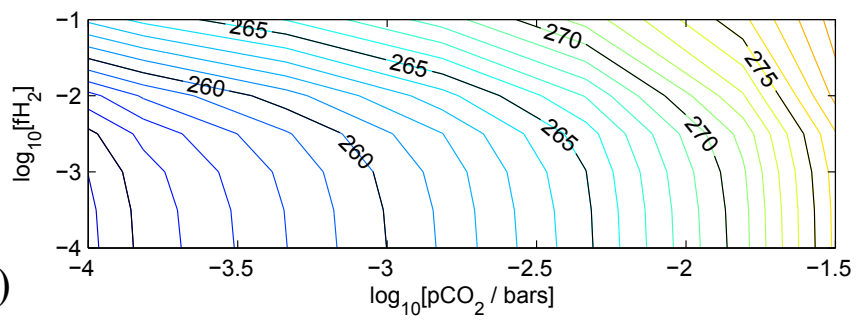

e)

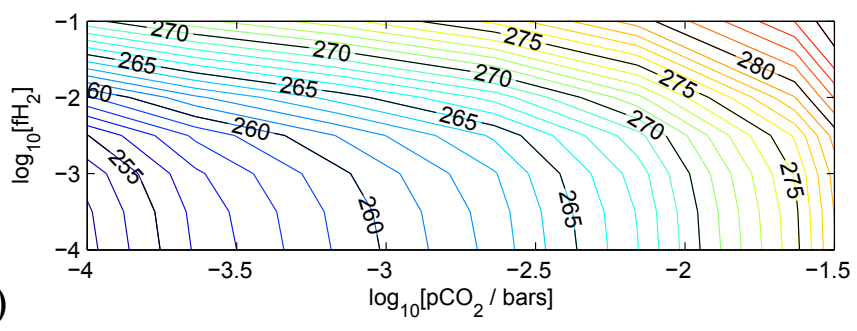

Figure 2: Radiative forcing due to the presence of hydrogen for a) moderate and b) high $\mathrm{H}_{2}$ $\mathrm{N}_{2}$ warming scenarios (see Table 1), as a function of surface temperature and atmospheric $\mathrm{CO}_{2}$ partial pressure. Calculated surface temperature in thermal equilibrium as a function of atmospheric $\mathrm{H}_{2}$ volume mixing ratio and $\mathrm{CO}_{2}$ partial pressure, for a reduced solar flux $F=$ $0.75 F_{0}$ and total atmospheric $\mathrm{N}_{2}$ amounts c) 1 , d) 2 and e) 3 times that of Earth today. Results are shown assuming no atmospheric methane and a surface albedo of 0.23 . 


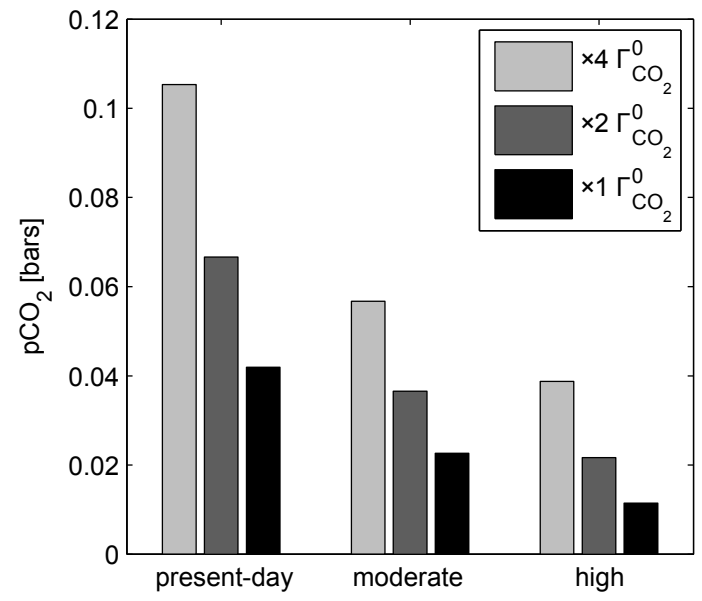

Figure 3: Atmospheric $\mathrm{CO}_{2}$ partial pressure assuming an abiotic carbonate-silicate weathering feedback, no seafloor weathering, and a solar flux $F=0.75 F_{0}$. The $\mathrm{H}_{2}$ and $\mathrm{N}_{2}$ levels for the present-day, moderate and high scenarios are given in Table 1. Results are shown for three values of the $\mathrm{CO}_{2}$ outgassing rate $\Gamma_{\mathrm{CO}_{2}}$ as a function of the present-day rate. 